Association for Information Systems

AIS Electronic Library (AISeL)

Winter 12-4-2009

\title{
Effects of IS Characteristics on the E-Business Success Factors for Small- and Medium-Sized Enterprises
}

She-l Chang

Chin-Tsang Ho

Li-Min Chang

Mei-Chen Chiang

Follow this and additional works at: https://aisel.aisnet.org/iceb2009

This material is brought to you by the International Conference on Electronic Business (ICEB) at AIS Electronic Library (AISeL). It has been accepted for inclusion in ICEB 2009 Proceedings by an authorized administrator of AIS Electronic Library (AISeL). For more information, please contact elibrary@aisnet.org. 


\title{
EFFECTS OF IS CHARACTERISTICS ON THE E-BUSINESS SUCCESS FACTORS FOR SMALL- AND MEDIUM-SIZED ENTERPRISES
}

\author{
She-I Chang ${ }^{1}$, Chin-Tsang $\mathrm{Ho}^{2}$, Li-Min Chang ${ }^{3}$, and Mei-Chen Chiang ${ }^{4}$ \\ Department of Accounting and Information Technology ${ }^{124}$ \\ Department of Information Management ${ }^{3}$ \\ National Chung Cheng University \\ 19actsic@ccu.edu.tw; ${ }^{2}$ miller@moeasmea.gov.tw; ${ }^{3}$ changclm@gmail.com; ${ }^{4}$ jen1001@gmail.com
}

\begin{abstract}
The current research presents a theoretically sound model on information systems (IS) characteristics' effects on end-users' perception of computer self-efficacy and outcome expectations. Based on the IS success model and the social cognitive theory, the relationship among factors with regard to small- and medium-sized enterprises (SMEs) in Taiwan is examined. Using mail survey, 284 usable responses are obtained, and the total response rate is recorded at $51.64 \%$. Structural equation modeling (SEM) is employed to assess the relationships among related constructs. In modeling the results of data analysis, it is shown that (1) there are no direct links between both information quality and service quality with computer self-efficacy, but the effect of system quality is observed; (2) the relationship between both system quality and service quality with outcome expectations is significant, but that with information quality is not; and (3) outcome expectations mediates the impacts of computer self-efficacy on end-users' satisfaction. Finally, the implications of the results are provided, and directions for future research are discussed.
\end{abstract}

Keywords: Social cognitive theory, IS success model, structural equation modeling (SEM), smalland medium-sized enterprises (SMEs)

\section{Introduction}

The rapid development of information communication technology (ICT) has spawned advancements in Internet applications. Firms are now said to be in the era of digital economy. However, along with the rapid development of e-business, firms around the world now encounter rigorous business competition. With greater customer demand and newly emerging technologies, firms must implement innovation and reforms in response to the significant challenges they face [12] [20]. With the influence of globalization and massive information diffusion, small- and medium-sized enterprises (SMEs) are hard-pressed to achieve their revenue targets.

In an unstable environment, managers should particularly recognize the operational environment, plan effective strategies, and invest in proper information technology (IT) and information systems (IS) to increase profits for the organization [1] [19]. Thus, to boost core competitiveness and positioning, sharing of important information through IS and communication technique may serve as the key strategies for SMEs to strengthen their market foothold. However, as technology is derived from human demand, the recognition of the system characteristics' influence and users' cognitive factors on IS satisfaction after the introduction of e-business in SMEs will be a significant research subject for improving organizations' IS efficacy and operational management.

The characteristics of the DeLone and McLean IS Success Model are studied by examining the influence of system characteristics on users' system use and satisfaction through information quality, system quality, and service quality of the system, and by further probing into its ultimate net benefit on individuals and organizations [10] [11]. The users' beliefs and internal expectation on computer applications are also critical issues for IS implementation. Marakas, et al. (2007) further indicated that the users' self-efficacy represents a complex psychological process. However, the belief of psychological constructs are also formed and used to guide human action [2] [3] [21] [22]. The Social Cognitive Theory aims to emphasize that individual cognition will be affected by external information which further influences the behavioral model.

To accomplish the objectives, this study aims to achieve the followings: (1) to examine the influences of system characteristics, information quality, system quality, and service quality on users' cognitive behavior; and (2) to recognize the influence of users' cognitive behavior on IS satisfaction. In analyzing the users' IS demand from the system characteristics in the IS success 
model and probes into the influence of users' psychological aspect on system satisfaction from the view of the social cognitive theory to elaborate and validate the research hypotheses. The research findings would act as critical criteria to improve SMEs e-business applications.

\section{Literature Review \\ Importance of e-Business}

The implementation of e-business is based on the view of firms and their application scope, which closely combines the importance of the knowledge system, related information, suppliers, partners, agents, employees, and clients through the Intranet, Extranet, and Internet. Likewise, it aims to reform and enhance original business procedures through Internet-based techniques.

E-commerce and e-business are widely applied in e-business. Nprris, et al. (2000) suggested that e-commerce includes two functions: selling the products or providing services through the Internet and making the procurement more efficient. E-business connects firms and the suppliers at different stages in the entire value chain through IT and enforces an open standard to reinforce operational performance.

E-commerce focuses on the efficiency of sales, marketing, and procurement. Kalakota and Robinson (2000) defined e-commerce as a transaction through digital media. Meanwhile, e-business companies not only include e-commerce but the drive of modern operation and integration of front and end business as well. E-business firms involve e-commerce, and they redefine the previous operational model through technical assistance, which leads to customers' maximum value. Therefore, e-business is an overall strategy, while e-commerce is simply an important part of e-business.

\section{Characteristics of SMEs and the Challenge for e-Business}

SMEs are small-scale firms that play a critical role in an environment characterized by rapid growth. They support industry development and serve as economic growth drivers. Scholars surmise that SMEs are small-scale or family-run firms with inadequate finances, insufficient capital, poor competitiveness, insufficient human resources, incomplete organizational structure, and weak industrial connections [1]. Rapid Internet and IT development, however, has led to new operational opportunities. SMEs should leverage IT, address their core competitiveness, and effectively combine external resources to respond to changing techniques and management.

With the emergence of a globalized and integrated world economy, industries all over the world encounter massive changes in both internal and external environments. They have adopted different market scales, organizational structures, and transaction measures to deal with these changes. To address the challenges of the new environment, firms must properly and fully implement IT and IS to create more business value and opportunities, support operation by IT/IS to obtain organizational efficiency and efficacy, reduce the costs involved, and reinforce information resources sharing. These have been the important issues in the field of information management in recent years [1] [12].

How to introduce IT successfully to increase competitiveness despite insufficient resources, capital, materials, and human resources is an important future strategy for SMEs. However, to enjoy the maximum benefits despite limited resources, SMEs should exercise caution in their e-business activities. Thus, the challenges and problems faced by SMEs are particularly critical in this study.

\section{The IS Success Model}

Since DeLone and McLean proposed the IS success model in 1992, there have been various researchers driving this model to examine IS implementation comprehensively [29] [31] [33] [34]. In 2003, DeLone and McLean further proposed a modified model to address change management and users' needs of the e-commerce era. The IS success model is simple and effective, and it can fully elaborate the important concept of a successful IS. Therefore, it is a significant theoretical and practical base for future studies [11].

Shannon and Weaver (1949) organized communication issues into three different levels: technical, semantic, and effectiveness. Furthermore, Mason's (1978) research adopted the communication theory as well as Shannon and Weaver's three level-concept to measure information output to explain and evaluate the user's behavioral change in IS communication application. Based on these concepts, DeLone and McLean reviewed over 180 articles in the period covering 1981 to 1988 , which constituted seven publications that proposed their IS success framework in 1992. In their literature reviews, DeLone and McLean conceptualized and taxonomized their model with six interrelated constructs of IS success, including system quality, information quality, system usage, users' satisfaction, individual impact, and organizational impact. The model likewise suggested that the constructs depend on one another and that they are sequential.

The concept of Service Quality was derived 
from marketing in the mid-1980s [27] [28]. After observing and recognizing IS usage, Pitt, Watson, and Kavan (1995) demonstrated that service quality could increase IS efficacy, and thus advised future researchers and system developers to consider this critical factor when constructing and measuring the system. The IS success model is widely accepted by scholars because it integrates recent research findings on IS using objective and specific concepts. After Pitt et al. (1995) emphasized service quality, and Seddon and Kiew (1996) proposed a multiple framework for the IS success model, DeLone and McLean further devoted themselves to the challenges of a successful IS in an e-commerce environment and modified the model to meet the business trends of the e-era [11] [31] [35]. After organizing the literature on IS success from 1993 to 2002 as sourced from a well-known IS periodical, DeLone and McLean modified the model and included service quality as an external variable to complete the original model. Hence, this new model can respond to the special operational requirement of growing IS in an e-commerce environment. The modified model is illustrated in Figure 1.

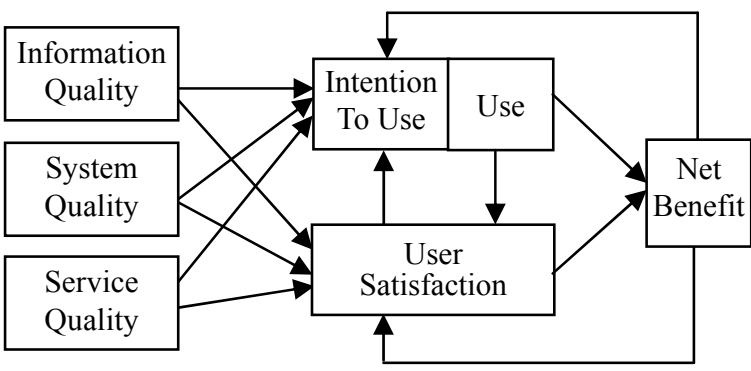

Figure 1. The Updated D and M IS Success Model Source: DeLone and McLean (2003)

With the prevalence of IT application, firms have encountered more diverse operational problems. Therefore, they must invest in the integration of IS, communication network, and e-commerce to obtain competitive advantages in a dynamic market. However, the measurement of an e-commerce system's success is a difficulty encountered mostly by firms. In this regard, the modified IS success model functions as a significant base for future studies [29] [33].

\section{The Social Cognitive Theory}

The social cognitive theory (SCT) is derived from the social learning theory (SLT). In 1986, Bandura, with authorization, launched the SCT in his book "Social Foundations of Thought and Action: A Social Cognitive Theory." The social cognitive theory suggests that individuals' behavioral model is based on the interaction among individual cognition, behavior, and environment. It emphasizes that individual cognition is affected by external information, which promotes changes in behavior [3] [4]. Within the perspective of SCT, humans are characterized in terms of the basic and unique capability of symbolizing; they are vicarious, possess forethought, and are capable of self-regulation and self-reflection. These characteristics provide humans with the cognitive means to determine their behavior [3] [4].

In recent years, the SCT has been widely discussed and applied in the field of social science, including modeling, skill training, behavioral rehearsal, self-monitoring, and contracting. Empirical studies on individual behavior, such as personalities and demographic characteristics, and the social stress of technology behavior have been widely cited by scholars [6] [7] [21] [22] [30]. Bandura emphasized that there are two sets of expectations that serve as the major cognitive force guiding human behavior. The first set relates to outcome expectations, while the second encompasses self-efficacy. Bandura defined outcome expectancy as a person's estimation that a given behavior would lead to certain outcomes, and explained efficacy expectation as the belief that one could well perform the behavior required to produce the outcomes [3].

Individual self-efficacy and outcome expectations are two core concepts of the SCT. Bandura suggested that people imagine the outcomes and infer their capacity to work for such, which will result in real actions through their individual execution and expected outcomes. In brief, with the self-efficacy belief, people perform the necessary actions and feel that their efforts are not in vain because of their expectations [2] [3].

\section{Research Method}

This study is based on the IS success model proposed by DeLone and McLean (2003) combined with Bandura's (1986) SCT. The goal is to determine how IS influenced user satisfaction through cognitive factors. In this section, the research model, development of research hypotheses, variable definition and measurement, and research design are elaborated. The theoretical research model is illustrated in Figure 2 below.

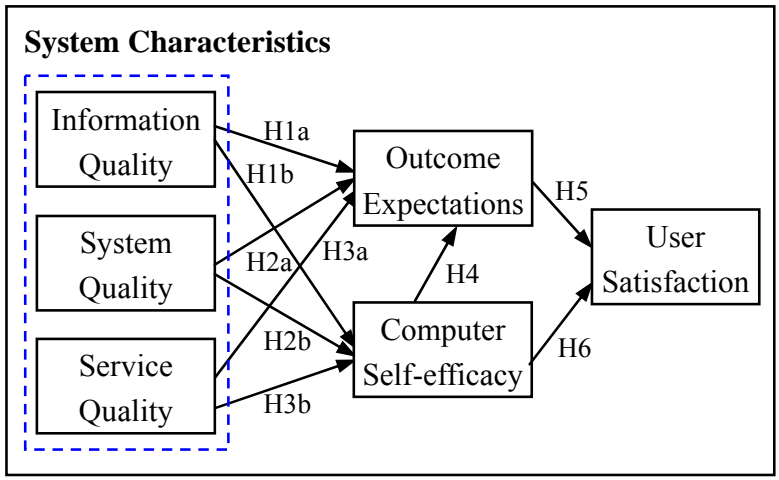

Figure 2. The Theoretical Research Model 


\section{The Development of Research Hypotheses}

With regard to the improvement of users' performance, IS potentially allows organizations or users to accomplish their goals. However, users at times would not accept or use IT. The main reason is the individuals' cognitive factors.

In relation to this, Davis (1989) suggested two important factors on IS usage: perceived usefulness and perceived ease of use, which were considered the core concepts of the technology acceptance model for the research on users' behavioral intention and technology usage. In a study on the factors of micro-computer usage, Igbaria, Guimaraes, and Davis (1995) suggested the external factors of different constructs: user characteristics, system characteristics (quality), and organization support, which influence users' usage of computer technology through belief in perceived usefulness and ease of use.

In a study on users' IT application, Davis (1989) cited the self-efficacy theory to elaborate on perceived usefulness and perceived ease of use, and observed their similarity to outcome expectations and self-efficacy in theory. Piccoli, Ahmad, and Ives (2001) probed into Web-based virtual learning environments and suggested that the system with sound technology quality, reliability, and was easy to be said had a significant and positive influence on individual self-efficacy, satisfaction, and performance.

In the study of social science, the self-efficacy theory was derived from the social cognitive theory. It likewise emphasized that the belief in self-efficacy is the key factor in human beings' drive, serving as the lead idea. The previously cited studies all indicated that beliefs in self-efficacy and outcome expectations were the most significant factors affecting individuals' behavior. The theory has been central in IT application in recent years as well [3] [9] [16] [30]. Thus, this study developed the following hypotheses:

H1a: With regard to IS usage, information quality has a positive and significant influence on users' outcome expectations.

H1b: With regard to IS usage, information quality has a positive and significant influence on users' computer self-efficacy.

H2a: With regard to IS usage, system quality has a positive and significant influence on users' outcome expectations.

$\mathrm{H} 2 \mathrm{~b}$ : With regard to IS usage, system quality has a positive and significant influence on users' computer self-efficacy.

$\mathrm{H} 3 \mathrm{a}$ : With regard to IS usage, service quality has a positive and significant influence on users' outcome expectations.

$\mathrm{H} 3 \mathrm{~b}$ : With regard to IS usage, service quality has a positive and significant influence on users' computer self-efficacy.

The SCT suggests that expectation is an important factor that influences individuals' activities. It indicates that the behavior would lead to a certain result. In a study on computer usage based on the SCT, Compeau and Higgins demonstrated the significant and positive relationship between computer self-efficacy and outcome expectations [3] [6] [7]. Thus, this study proposed the following hypothesis:

H4: With regard to IS usage, computer self-efficacy has a positive and significant influence on users' outcome expectations.

People's beliefs on performance accomplishments or the attitude towards IS would influence their actions, such as their effort to achieve such targets or their persistence in facing difficulties or failure and recovery from obstacles. Thus, people's beliefs influence their ability to work under pressure. Moreover, the SCT suggests that expectation is an important factor in people's behavior. From the psychological perspective, people tend to accomplish things that are beneficial to them. Expectation is particularly significant when using a new computer technology and in performance [3] [6] [7].

According to the study of Compeau and Higgins (1995b) on computer application, users' performance outcome expectations and personal outcome expectations have a significant and negative influence on performance. In the SCT, Bandura (1986) suggested that when people possess better self-efficacy, they are capable of better performance. However, Bandura failed to emphasize the relationship between outcome expectations and performance; instead, he suggested that outcome expectations were a significant factor on users' performance. Bandura further elaborated that when people expect more from the results, they tend to perform better. Singh, Watson, and Watson (2002) likewise stressed that IS success was closely related to users' acceptance of IS and system usage, and it influenced users' job performance and satisfaction. Marakas, $\mathrm{Yi}$, and Johnson (1998) probed into the multiple constructs of computer self-efficacy and categorized them into general computer self-efficacy and specific computer self-efficacy. They further suggested that computer self-efficacy beliefs would influence users' computer ability and performance. Thus, this study proposed the following hypotheses:

H5: With regard to IS usage, outcome expectations have a positive and significant influence on users' satisfaction. 
H6: With regard to IS usage, computer self-efficacy has a positive and significant influence on users' satisfaction.

\section{Definition and Measurement of Variables}

In this section, the variables' operational definitions and a summary of related literature are provided, as well as questions on the scales and the scales per se, as organized in Tables 1 and 2.

Table 1. Operational Definition of Variables

\begin{tabular}{|c|c|c|}
\hline Names of variables & Operational definitions of variables & Reference \\
\hline Information quality & $\begin{array}{l}\text { Information connection, timeliness, and accuracy of information upon } \\
\text { IS }\end{array}$ & {$[10][11][34][35]$} \\
\hline System quality & Ease level of specific IS perceived by the users & {$[10][11][34][35]$} \\
\hline Service quality & $\begin{array}{l}\text { IS service providers' development of a positive attitude and } \\
\text { relationship with users, their overall support of communication, and } \\
\text { users' permission to access related and high-quality services }\end{array}$ & {$[10][11][31][34][35]$} \\
\hline Computer self-efficacy & People's idea on their computer ability to accomplish a work & [6] [16] \\
\hline Outcome expectations & $\begin{array}{l}\text { People's views on things which will influence their behavior and lead to } \\
\text { certain results }\end{array}$ & [3] [7] \\
\hline User satisfaction & Users' overall experience and attitude after using IS & [5] [34] [35] \\
\hline
\end{tabular}

Table 2. Sources of Variable Scales

\begin{tabular}{lccc}
\hline \multicolumn{1}{c}{ Names of variables } & Items & Scale & Sources \\
\hline Information quality & 8 items & 7 -point scale & {$[35]$} \\
System quality & 10 items & 7 -point scale & {$[35]$} \\
Service quality & 22 items & 7 -point scale & {$[35]$} \\
Computer self-efficacy & 10 items & 11-point scale & {$[6]$} \\
Outcome expectations & 11 items & 7 -point scale & {$[7]$} \\
User satisfaction & 4 items & 7-point scale & {$[35]$} \\
\hline
\end{tabular}

\section{Research Design}

To validate the theoretical model successfully, a survey was conducted for this study; samples were obtained by designing and distributing questionnaires. The targets were IS users of SMEs in the "Bridging the Digital Divide of SMEs" project of the Ministry of Economic Affairs' Small and Medium Enterprise Administration unit. To ensure the questionnaire's reliability and validity, this study not only constructed the model according to related literature but designed the questionnaire according to related fields as well. Further, the current research invited experts and scholars to examine and modify the questionnaire's content to enhance content validity, as well as to validate the meaning of the questions through a pretest and pilot test.

To accomplish the research purpose and validate the hypotheses, data analysis was divided into two stages. First, descriptive statistical analysis of the returned samples was conducted using SPSS for Windows, as well as reliability and validity tests. The second stage involved the research model's validation. This study estimated the measurement model and the structural model using the structural equations modeling (SEM) technique to assess the relationships among related constructs.

SEM involves two key characteristics: (1) it can estimate multiple regression equations that are individual and dependent, and (2) it can determine the potential concepts in the dependent relations and explain the measurement error [13] [14]. The current study planned precise research procedures and evaluated the software for data analysis to acquire reliable statistical results and analytical findings.

\section{Data Analysis and Results \\ Basic Information Analysis of the Samples}

This study involved SMEs with at least one year of e-business of digital divide experience in the "Bridging the Digital Divide of SMEs" Project. With the assistance from the Information Service Industry Association of R.O.C. and the Small and Medium Enterprise Administration of the Ministry of Economic Affairs, the study successfully distributed and retrieved the questionnaires. The sample collection was conducted from 30 August 2007 to 30 September 2007. There were a total of 550 questionnaires distributed, and 460 were returned. After the invalid ones were eliminated, there were a total of 284 valid questionnaires and 176 invalid ones. The overall valid questionnaire 
return rate was $51.64 \%$.

Following the frequency distribution statistical analysis using SPSS, the valid returned questionnaires included three sections. In terms of users' basic information, majority of the respondents were female (155 respondents, 54.6\%). With regard to educational level, the majority graduated from college/university (71.8\%). With regard to the type of company, the majority was in the service industry (123 people, $43.3 \%$ ). In terms of IS application data, 125 companies have introduced a sales, distribution, trade, and purchasing system (44\%); 138 have introduced an accounting information management system $(48.6 \%)$; 97 have introduced a personnel and salary management system (34.2\%); 129 have introduced a client management system (45.4\%); and 89 have introduced a financial management system $(31.3 \%)$.

\section{Tests of Reliability and Validity}

Reliability refers to the consistency or stability of the questionnaire results. However, lower errors will lead to a higher level of reliability. In other words, a better reliability measurement will result in the consistency and stability of results. This study measures questionnaire reliability using Cronbach's alpha, as well as the consistency of the items.

The results indicate that the alpha of all constructs is over 0.8 . The alpha of the overall reliability reached 0.9611 . Thus, the questionnaire employed in this study has a high level of consistency and stability. The validity test in the first stage includes content validity and convergent validity. Content validity is a systematic test on the propriety of a questionnaire's content, the scale's content, and the items of the scale [14]. To ensure content validity and allow the items to reflect the constructs' real meanings, this study designed the questions using theoretical concepts as found in the literature. After the initial translation, accounting and IT scholars were invited to assess and modify the questionnaire as needed. After the first draft, experts were again invited to modify the questions based on the pretest and pilot test results.

The questionnaire design of this study is modified according to the scale of its English version. Thus, with regard to the translated scale's common method variance, this study observes the items' convergence by exploratory factory analysis (EFA) [32, p.893]. When extracting the factors, the study applies the principal component analysis with Varimax rotation as developed by Kaiser in 1958 for orthogonal rotation method to maximize large factor loading and minimize small factor loading before rotation. With regard to the measurement of the factor analysis, the factor loadings greater than 0.5 in 284 valid samples are considered practically significant [14, p.128]. The factor analysis results on the variables are illustrated in Tables 3 and 4 below.

\section{Tests of Structural Equation Model}

This study conducts a measurement model test through confirmatory factor analysis (CFA) using AMOS 5.0 of SEM. According to Hair et al. (2006), the measurement in SEM offers suggestions based on 5 7 indices for one construct. After confirming the normality, the model can be measured by model fit indices and criteria. To measure the models without affecting the constructs' reliability and validity, this study eliminates the items with a lower factor loading and continues the fit model measurement according to the criteria by the suggestions pertaining to fit indices [13] [14]. After modification, the indices are as follows: $\mathrm{GFI}=0.819$, $\mathrm{X}^{2} / \mathrm{df}=1.937, \mathrm{RMR}=0.060, \mathrm{NFI}=0.864, \mathrm{CFI}=0.929$, RMSEA $=0.058$ and AGFI $=0.793$.

With regard to the measurement of the constructs' reliability and validity, Hair et al. (2006) suggested that composite reliability and average variance extracted could be applied. Composite reliability refers to a higher level of internal consistency, and reliability leads to better consistency. Generally, 0.7 is the acceptable criterion. The average variance extracted (AVE) of each construct should be more than 0.5. The measurement result of the composite reliability of the constructs in this study is as follows: information quality $=0.898$; system quality $=0.799$; service quality $=0.909$; outcome expectations $=0.875$; computer self-efficacy $=0.857 ; \quad$ and overall satisfaction $=0.799$.

The average variance extracted matches the criterion 0.5. Except for computer self-efficacy with a 0.473 value, which is lower, the composite reliability reaches 0.857 . Thus, the constructs of this study indicate a certain level of reliability and validity.

Discriminant validity aims to recognize the multicollinearity among the variables. The related test in this study is based on the Pearson correlation matrix to assess multicollinearity and determine adequate discriminant validity. Using the radical AVE of the constructs in data analysis, the study substitutes the variables and the correlation coefficient, and the result demonstrates that the radical AVEs are more than the correlation coefficients of other variables. Thus, this study infers that multicollinearity is not significant among the variables [7] [8] [14]. The test results are displayed in Table 5 below.

After confirming the constructs' reliability and validity, the current study conducts path analysis of the variables. After modifying the structural model, the indices are as follows: $\mathrm{GFI}=0.813, \mathrm{X}^{2} / \mathrm{df}=1.996$, 
RMR $=0.067, \quad \mathrm{NFI}=0.813, \quad \mathrm{CFI}=0.924$, RMSEA $=0.059$, and AGFI $=0.787$. The significance of the path coefficient is illustrated in Table 6 below. With regard to the constructs explained in the variance $\left(\mathrm{R}^{2}\right)$, the overall satisfaction is $65.1 \%$; the outcome expectations is $65.8 \%$; and the computer self-efficacy is $7.1 \%$.

Table 3. Factor Analysis Results of Computer Self-efficacy and Outcome Expectations

\begin{tabular}{cccccccc}
\hline $\begin{array}{c}\text { Names of } \\
\text { variables }\end{array}$ & Items & $\begin{array}{c}\text { Factor } \\
\text { loading }\end{array}$ & $\begin{array}{c}\text { Explained } \\
\text { variance (\%) }\end{array}$ & $\begin{array}{c}\text { Names of } \\
\text { variables }\end{array}$ & Items & $\begin{array}{c}\text { Factor } \\
\text { loading }\end{array}$ & $\begin{array}{c}\text { Explained } \\
\text { variance (\%) }\end{array}$ \\
\hline & 9 & 0.858 & & & 2 & 0.833 \\
& 3 & 0.855 & & & 4 & 0.826 \\
& 6 & 0.850 & & & 1 & 0.812 \\
Computer & 1 & 0.849 & & Outcome & 3 & 0.796 \\
Self-efficacy & 5 & 0.846 & & & 0.789 & \\
& 7 & 0.846 & 34.735 & Expectations & 9 & 0.772 & 31.758 \\
& 10 & 0.844 & & & 6.756 & 0.742 \\
\\
\hline
\end{tabular}

Table 4. Factor Analysis Results of the Different Constructs

\begin{tabular}{|c|c|c|c|c|c|c|c|}
\hline $\begin{array}{l}\text { Names of } \\
\text { variables }\end{array}$ & Items & $\begin{array}{l}\text { Factor } \\
\text { loading }\end{array}$ & $\begin{array}{c}\text { Explained } \\
\text { variance( } \%)\end{array}$ & $\begin{array}{l}\text { Names of } \\
\text { variables }\end{array}$ & Items & $\begin{array}{l}\text { Factor } \\
\text { loading }\end{array}$ & $\begin{array}{l}\text { Explained } \\
\text { variance(\%) }\end{array}$ \\
\hline \multirow{9}{*}{$\begin{array}{c}\text { Information } \\
\text { quality }\end{array}$} & 2 & 0.785 & \multirow{10}{*}{28.367} & & 7 & 0.824 & \multirow{22}{*}{55.180} \\
\hline & 10 & 0.760 & & & 4 & 0.804 & \\
\hline & 5 & 0.755 & & & 8 & 0.792 & \\
\hline & 6 & 0.755 & & & 5 & 0.776 & \\
\hline & 3 & 0.750 & & & 19 & 0.766 & \\
\hline & 7 & 0.747 & & & 11 & 0.764 & \\
\hline & 1 & 0.735 & & & 18 & 0.752 & \\
\hline & 9 & 0.721 & & & 17 & 0.752 & \\
\hline & 4 & 0.720 & & & 1 & 0.748 & \\
\hline \multirow{6}{*}{ System Quality } & 8 & 0.647 & & & 22 & 0.746 & \\
\hline & 4 & 0.805 & \multirow{5}{*}{17.191} & Service & 6 & 0.744 & \\
\hline & 3 & 0.776 & & Quality & 12 & 0.740 & \\
\hline & 2 & 0.772 & & & 21 & 0.738 & \\
\hline & 5 & 0.745 & & & 10 & 0.738 & \\
\hline & 1 & 0.742 & & & 15 & 0.735 & \\
\hline \multirow{4}{*}{ Satisfaction } & 4 & 0.806 & \multirow{4}{*}{14.849} & & 20 & 0.729 & \\
\hline & 3 & 0.779 & & & 14 & 0.728 & \\
\hline & 2 & 0.775 & & & 3 & 0.710 & \\
\hline & 1 & 0.772 & & & 9 & 0.704 & \\
\hline System Quality & 7 & 0.941 & \multirow{3}{*}{11.927} & & 2 & 0.685 & \\
\hline 2 & 8 & 0.923 & & & 16 & 0.675 & \\
\hline (Reverse item) & 6 & 0.904 & & & 13 & 0.670 & \\
\hline
\end{tabular}

Table 5. Correlations and AVE

\begin{tabular}{ccccccc}
\hline Construct & AVE & Inf-Q & Sys-Q & Ser-Q & Satis & Out-E \\
\hline Inf-Q & 0.595 & $\mathbf{0 . 7 7 1}$ & & & & \\
Sys-Q & 0.631 & 0.615 & $\mathbf{0 . 7 9 4}$ & & & \\
Ser-Q & 0.582 & 0.763 & 0.635 & $\mathbf{0 . 7 6 3}$ & & \\
Satis & 0.697 & 0.640 & 0.585 & 0.723 & $\mathbf{0 . 8 3 5}$ & \\
Out-E & 0.613 & 0.618 & 0.561 & 0.725 & 0.716 & $\mathbf{0 . 7 8 3}$ \\
CSE & 0.473 & 0.210 & 0.240 & 0.213 & 0.249 & 0.233 \\
\hline
\end{tabular}

The diagonal elements (in bold) are the square root of the average variance extracted (AVE).

The off-diagonal elements are the correlations among constructs. For discriminant validity, the diagonal elements should be larger than the off-diagonal elements.

Inf-Q=Information Quality; Sys-Q=System Quality; Ser-Q=Service Quality; Satis=Satisfaction; Out-E=Outcome Expectation; CSE $=$ Computer Self-efficacy. 
Table 6. Path Findings via Amos Analysis

\begin{tabular}{|c|c|c|c|c|c|}
\hline Path links & & & $\begin{array}{l}\text { Standardized } \\
\text { Estimate }\end{array}$ & C.R. & Results \\
\hline Information Quality & $\rightarrow$ & $\begin{array}{l}\text { Computer } \\
\text { Self-efficacy }\end{array}$ & 0.088 & 0.656 & NS \\
\hline System Quality & $\rightarrow$ & $\begin{array}{l}\text { Computer } \\
\text { Self-efficacy }\end{array}$ & $0.177 *$ & 1.802 & $\mathrm{~S}$ \\
\hline Service Quality & $\rightarrow$ & $\begin{array}{l}\text { Computer } \\
\text { Self-efficacy }\end{array}$ & 0.026 & 0.190 & NS \\
\hline Information Quality & $\rightarrow$ & $\begin{array}{l}\text { Outcome } \\
\text { Expectations }\end{array}$ & 0.016 & 0.182 & NS \\
\hline System Quality & $\rightarrow$ & $\begin{array}{l}\text { Outcome } \\
\text { Expectations }\end{array}$ & $0.149 * *$ & 2.241 & $\mathrm{~S}$ \\
\hline Service Quality & $\rightarrow$ & $\begin{array}{l}\text { Outcome } \\
\text { Expectations }\end{array}$ & $0.666 * * *$ & 6.626 & $\mathrm{~S}$ \\
\hline $\begin{array}{l}\text { Computer } \\
\text { Self-efficacy }\end{array}$ & $\rightarrow$ & $\begin{array}{l}\text { Outcome } \\
\text { Expectations }\end{array}$ & $0.071 *$ & 1.643 & $\mathrm{~S}$ \\
\hline $\begin{array}{l}\text { Outcome } \\
\text { Expectations }\end{array}$ & $\rightarrow$ & Satisfaction & $0.786 * * *$ & 12.653 & $\mathrm{~S}$ \\
\hline $\begin{array}{l}\text { Computer } \\
\text { Self-efficacy }\end{array}$ & $\rightarrow$ & Satisfaction & 0.069 & 1.515 & NS \\
\hline
\end{tabular}

C.R. of Standard Regression Weights of the constructs: more than 1.64, 1.96, 2.58

$* \mathrm{p}<0.1,{ }^{* *} \mathrm{p}<0.05, * * * \mathrm{p}<0.01$ statistical level. ( S: support; NS: not support )

This study aims to determine the influence of IS characteristics on user satisfaction among SMEs engaged in e-business. It presents a theoretical model and proposes nine hypotheses. It gathers the users' cognition and perception of IS usage through a written survey. After managing the collected data and statistical analysis, the study demonstrates that $\mathrm{H} 2 \mathrm{a}, \mathrm{H} 2 \mathrm{~b}, \mathrm{H} 3 \mathrm{a}, \mathrm{H} 4$, and $\mathrm{H} 5$ are supported, while $\mathrm{H} 1 \mathrm{a}, \mathrm{H} 1 \mathrm{~b}, \mathrm{H} 3 \mathrm{~b}$ and H6 are not. The research findings and suggestions are discussed as follows.

\section{Conclusions and Suggestions}

The IS success model operates IS information quality, system quality, and service quality to probe into IT's influence on users' perception of system usage and their satisfaction. Thus, the impact on people and organizations can be recognized [10] [11]. However, can IT increase the efficacy of people and organizations? An analysis of the system cannot fully elaborate all possible factors. Thus, a more general study on external factors, the users' computer capability, and the influence of internal computer self-efficacy on organizational and individual effects has become a central issue in modern research on IT application [21] [29] [33].

The SCT emphasizes that human beings' behavioral model is based on the interaction among individual cognition, behavior, and the environment. Users' behavior will be affected by the change in individual cognition through external information [2] [22]. Thus, this study combines the IS success model and the SCT to propose a theoretical model. It probes into the influence of users' cognitive behavior on their satisfaction with SMEs by system characteristics to elaborate the validation of the hypotheses in this study's theoretical model. According to the data analysis results, this study proposes suggestions for SMEs, information service providers, the government, and the academia.

\section{Suggestions for SMEs}

With the emergence of the digital economy, traditional brick-and-mortar businesses can no longer satisfy internal and external business operations [18]. Thus, Internet IS introduction for the sharing of external and internal information resources has become an important strategy for firms to enhance their business efficiency and market competitiveness [1]. Data analysis results demonstrate that in IS application, SMEs should not only value technology techniques but likewise pay attention to factors such as human interface, 
better service quality, and users' cognition and behavior to construct a successful IS that will allow SMEs to create more profits in an extremely competitive economic environment.

\section{Suggestions for IT Service Providers}

In recent years, due to cost limitations, IS development in SMEs has tended to be based on outsourcing. When constructing IS, SMEs need the assistance of software and hardware suppliers to overcome technical difficulties and their lack of experience in this particular field. Thus, information service providers play a significant role in e-business. SMEs' increasing e-demand, however, has compelled them to turn to the market for information suppliers. Service quality upgrading is an important issue in the information service industry's future development. Upon successful IS development, the system design should be based on human interface, such as digital video and sound, video conference, and interactive interface [1] [26]. This study suggests that the information service industry should plan user functions in different levels to arrive at better system quality. In addition, a number of scholars suggest that IS service providers (such as service companies and information personnel) should have excellent communication skills because effective communication cannot only lead to the identification of users' real demands but demonstrate the firms' sincerity as well, which is important for maintaining long-term customer relationship [15].

\section{Suggestions for the Government}

SMEs are the drivers of the economy and constitute the base that stabilizes the social structure and creates job opportunities. Thus, an in-depth study of the problems encountered by SMEs in e-business becomes significant for the government. When facing severe competition, firms should construct an effectively integrated IS to increase their competitive advantages. An integrated IS has become more and more important in IS development in recent years because the system involves the integration of firms' operational information and business process. It can support not only firms' operations and schedules but connect front and end business as well. It is useful for integrating internal resources and standardizing procedures [12] [20].

\section{Suggestions for the Academia}

To measure IS satisfaction effectively, this study attempted to combine the IT and cognitive psychology theories. The result was a research model for empirical study and data validation. Although the overall model fit should be improved, the model was based on innovative and human concepts that supplement the disadvantages of technology in neglecting humanity and values procedure.

The model used in this study and the findings may be tapped as the criteria by future researchers who will delve into the same topic. According to the data analysis, the propriety of the number of items and the length of questionnaire are significantly related to the model fit's measurement. Many scholars suggest that SEM measurement should be based on five to seven indicators for each construct, and the variables in model construction should exceed this number [14].

Respondents tend to be impatient with long questionnaires, which results in invalid questionnaires and directly affects the quality of research findings. A number of scholars emphasize that to construct a valid scale, its validity, reliability, correlation, and legitimacy should be established, and the scale quality should be simple and efficient [24] [32]. For studying different phenomena and the problems involved in IT application, it is important to apply a suitable theory and design a proper questionnaire when collecting data for further analysis.

\section{References}

[1]. Al-Qirim, N. "An Empirical Investigation of an e-commerce Adoption-Capability Model in Small Businesses in New Zealand," Electronic Markets, 15(4), 2005,pp.418-437.

[2]. Bandura, A. Self-Efficacy: The Exercise of Control. New York: W. H. Freeman, 1997.

[3]. Bandura, A. Social Foundations of Thought and Action: A Social-cognitive Theory. Englewood Cliffs, NJ: Prentice-Hall, 1986.

[4]. Bandura, A. "Human agency in social cognitive theory," American Psychologist, 44, 1989, pp.1175-1184.

[5]. Bhattacherjee, A.. "Understanding Information Systems Continuance: An Expectation-Confirmation Model," MIS Quarterly, 25(3), 2001, pp.351-370.

[6]. Compeau, D.R. and Higgins, C.A. "Computer Self-Efficacy: Development of a Measure and Initial Test," MIS Quarterly, 19(2), 1995a, pp.189-211.

[7]. Compeau, D.R. and Higgins, C.A. "Application of Social Cognitive Theory to Training for Computer Skills," Information Systems Research, 6(2), 1995b, pp.118-143.

[8]. Compeau, D.R., Higgins, C.A., and Huff, S. "Social Cognitive Theory and Individual Reactions to Computing Technology: A Longitudinal Study," MIS Quarterly, 23(2), 1999, pp.145-158.

[9]. Davis, F.D. "Perceived Usefulness, Perceived Ease of Use, and User Acceptance of 
Information Technology," MIS Quarterly, 13(3), 1989, pp.319-339.

[10].DeLone, W.H. and McLean, E.R. "Information Systems Success: The Quest for the Dependent Variable," Information Systems Research, 3(1), 1992, pp.60-95.

[11].DeLone, W.H. and McLean, E.R. "The DeLone and McLean Model of Information Systems Success: A Ten-Year Update," Journal of Management Information Systems, 19(4), 2003, pp.9-30.

[12]. Gattiker, T.F. and Goodhue, D.L. "What Happens After ERP Implementation: Understanding The Impact of Inter-Dependence and Differentiation on Plant-Level Outcomes," MIS Quarterly, 29(3), 2005, pp.559-585.

[13]. Gefen, D., Straub, D.W. and Boudreau, M.C. "Structural Equation Modeling and Regression: Guideline for Research Practice," Communications of the Association for Information Systems, 4(7), 2000, pp.1-70.

[14].Hair, J.F., Anderson, R.E., Tatham, R.L. and Black, W.C. Multivariate Data Analysis with Reading 6rd. Printice Hall, 2006.

[15].Hornik, S., Chen, H.G., Klein, G. and Jiang, J.J. "Communication Skills of IS Providers: An Expectation Gap Analysis From Three Stakeholder Perspectives," IEEE Transactions on Professional Communication, 46(1), 2003, pp.17-34.

[16].Igbaria, M. and Iivari, J. "The Effects of Self-efficacy on Computer Usage," Omega, Int. J. Mgmt Sci., 23(6), 1995, pp.587-605.

[17]. Igbaria, M., Guimaraes, T. and Davis, G.B. "Testing the Determinants of Microcomputer Usage via a Structural Equation Model," Journal of Management Information Systems, 11(4), 1995, pp.87-114.

[18].Kalakota, R. and Robinson, M. e-Business 2.0: Roadmap for Success. Addison-Wesley Longman Inc, 2000.

[19].Li, M and Ye, L.R. "Research Information technology and firm performance: Linking with environmental, strategic and managerial contexts," Information \& Management, 35(4), 1999, pp.43-51.

[20].Liang, H., Saraf, N., Hu, Q., and Xue, Y. "Assimilation of Enterprise Systems: The Effect of Institutional Pressures and The Mediating Role of Top Management," MIS Quarterly, 31(1), 2007, pp.59-87.

[21].Marakas, G.M., Johnson, R.D. and Clay, P.F. "The Evolving Nature of the Computer Self-Efficacy Construct: An Empirical Investigation of Measurement Construction, Validity, Reliability and Stability Over Time," Journal of the Association for Information Systems, 8(1), 2007, pp.16-46.
[22].Marakas, G.M., Yi, M.Y. and Johnson, R.D. "The Multilevel and Multifaceted Character of Computer Self-Efficacy: Toward Clarification of the Construct and an Integrative Framework for Research," Information Systems Research, 9(2), 1998, pp. 126-163.

[23].Mason, R.O. "Measuring information output: a communication systems approach," Information and Management, 1(5), 1978, pp.219-34.

[24]. Melone, N.P. "A Theoretical Assessment of the User-Satisfaction Construct in Information Systems Research," Management Science, 36(1), 1990, pp.76-91.

[25].Nprris G., Hurley, J.R., Hartley, K.M., Dunleavy, J.R. and Balls, J.D. E-Business and ERP: Transforming the Enterprise. John Wiley and Sons, Inc, 2000.

[26].Olsen, K. A., and Sætre, P. "IT for niche companies: Is an ERP system the solution?," Information Systems Journal, 17(1), 2007, pp.37-58.

[27].Parasuraman, A., Berry, L.L. and Zeithaml, V.A. "A Conceptual Model of Service Quality and Its Implications for Future Research," Journal of Marketing, 49(4), 1985, pp.41-50.

[28].Parasuraman, A., Berry, L.L. and Zeithaml, V.A. "SERVQUAL: A Multiple Item Scale for Measuring Consumer Perceptions of Service Quality," Journal of Retailing, 64(1), 1988, pp.12-40.

[29].Petter, S., DeLone, W. H., and McLean, E. R. "Measuring information systems success: models, dimensions, measures, and interrelationships," European Journal of Information Systems, 17, 2008, pp.236-263.

[30].Piccoli, G., Ahmad, R. and Ives, B. "Web-Based Virtual Learning Environments: A Research Framework and A Preliminary Assessment of Effectiveness in Basic IT Skills Training," MIS Quarterly, 25(4), 2001, pp.401-426.

[31].Pitt, L.F., Watson, R.T. and Kavan, C.B. "Service Quality: A Measure of Information Systems Effectiveness," MIS Quarterly, 19(2), 1995, pp.173-188.

[32].Podsakoff, P.M., MacKenzie, S.B., Lee, J.Y., Podsakoff, N.P. "Common Method Biases in Behavioral Research: A Critical Review of the Literature and Recommended Remedies," Journal of Applied Psychology, 88(5), 2003, pp.879-903.

[33]. Sabherwal, R., Jeyaraj, A. and Chowa, C. "Information systems success: individual and organizational determinants," Management Science, 52(12), 2006, pp.1849-1864.

[34].Seddon, P.B. "A Respecification and Extension of the DeLone and McLean Model 
of IS Success," Information Systems Research, 8(3), 1997, pp.240-253.

[35].Seddon, P.B. and Kiew, M.Y. "A Partial Test and Development of DeLone and McLean's Model of IS Success," Australian Journal of Information Systems, 4(1), 1996, pp.90-109.
[36].Shannon, C.E. and Weaver, W. The Mathematical Theory of Communication, University of Illinois Press. Urbana, IL, 1949.

[37]. Singh, S.K., Watson, H.J. and Watson, R.T. "EIS support for the strategic management process," Decision Support Systems, 33(1), 2002, pp.71-85. 